\title{
Update on endovascular therapies for cerebral vasospasm induced by aneurysmal subarachnoid hemorrhage
}

\author{
Christina M. Sayama, B.S., James K. LiU, M.D., AND \\ William T. Couldwell, M.D., Ph.D. \\ Department of Neurosurgery, University of Utah School of Medicine, Salt Lake City, Utah
}

\begin{abstract}
$\checkmark$ Cerebral vasospasm remains a major source of morbidity and death in patients with aneurysmal subarachnoid hemorrhage (SAH). When vasospasm becomes refractory to maximal medical management consisting of induced hypertension and hypervolemia and administration of calcium channel antagonists, endovascular therapies should be considered. The primary goal of endovascular treatment is to increase cerebral blood flow to prevent cerebral infarction. Two of the more frequently studied endovascular treatments are transluminal balloon angioplasty and intraarterial papaverine infusion. These two have been used either alone or in combination for the treatment of vasospasm. Other pharmacological vasodilating agents currently being investigated are intraarterial nimodipine, nicardipine, verapamil, and milrinone. Newer intraarterial agents, such as fasudil and colforsin daropate, have also been investigated. In this article the authors review the current options in terms of endovascular therapies for treatment of cerebral vasospasm. The mechanism of action, technique of administration, clinical effect and outcomes, and complications of each modality are discussed.
\end{abstract}

\section{KEY WORDS • cerebral vasospasm • subarachnoid hemorrhage • endovascular therapy • balloon angioplasty • papaverine}

$\mathrm{C}$ EREBRAL vasospasm continues to be one of the leading causes of death and disability following SAH. ${ }^{28}$ Blood products that collect after SAH and remain in prolonged contact with the cerebral vessel walls induce vasospasm, resulting in narrowing of the vessel lumen and compromised $\mathrm{CBF}$ and oxygenation. This can result in ischemic sequelae manifested by the onset of confusion, a decreased level of consciousness, speech and motor impairments, increasing blood pressure, and a worsening headache. Approximately $7 \%$ of patients who reach neurosurgical referral centers will die of vasospasm and another $7 \%$ will be seriously injured because of this condition. The diagnosis of cerebral vasospasm is based on both angiographic changes and clinical neurological changes. Although $70 \%$ of patients may experience angiographic vasospasm, only 20 to $30 \%$ will exhibit delayed ischemic neurological deficits. ${ }^{28,32}$

Current therapy for prevention and treatment of symptomatic cerebral vasospasm includes triple-H (hypertension, hypervolemia, and hemodilution) therapy, ${ }^{3}$ calcium channel antagonists,,$^{15}$ early surgery with clot removal, ${ }^{22}$ and cerebrospinal fluid drainage in the lumbar region. ${ }^{31}$ However, if vasospasm is refractory to maximal medical management, then endovascular therapies such as transluminal balloon angioplasty, intraarterial infusions of vasodilating agents, or a combination of options should be

Abbreviations used in this paper: $\mathrm{ACA}=$ anterior cerebral artery; cAMP = cyclic adenosine monophosphate; $\mathrm{CBF}=$ cerebral blood flow; cGMP = cyclic guanosine monophosphate; $\mathrm{CT}=$ computed tomography; ICA = internal carotid artery; ICP = intracranial pressure; $\mathrm{MCA}=$ middle cerebral artery; $\mathrm{SAH}=$ subarachnoid hemorrhage; $\mathrm{TCD}=$ transcranial Doppler; $\mathrm{VA}=$ vertebral artery. considered. The primary goal of endovascular treatment for symptomatic vasospasm is to increase $\mathrm{CBF}$ to prevent infarction. Delays in instituting therapy for vasospasm can lead to irreversible cerebral infarction and a poor neurological outcome.

Endovascular treatment for vasospasm involves mechanical dilation of vasospastic arteries by using inflatable balloons and/or delivery of intraarterial pharmacological vasodilators. Eskridge, et al., ${ }^{13}$ proposed the following criteria to determine when endovascular therapy should be used: 1) new onset of neurological deficit not due to other causes; 2 ) no evidence of established cerebral infarction on CT scans; 3) persistent deficit despite triple$\mathrm{H}$ therapy; and 4) angiographic evidence of vasospasm in a distribution that can explain the deficit. In this article, we review the current endovascular therapies available to treat refractory symptomatic vasospasm, including transluminal balloon angioplasty and intraarterial infusions of vasodilating agents. Some vasodilators that have been used are papaverine, nimodipine, nicardipine, verapamil, milrinone, fasudil, and more recently, colforsin daropate..$^{53}$ We discuss the mechanism of action, technique of administration, clinical effects and outcomes, and complications of each therapy.

\section{Transluminal Balloon Angioplasty}

One of the most commonly used techniques to treat refractory symptomatic vasospasm is transluminal balloon angioplasty, also known as percutaneous transluminal angioplasty. This technique was initially described by Dotter and Judkins ${ }^{11}$ in 1964 for the treatment of peripheral arteriosclerotic obstruction, and since has been applied 
to the treatment of atherosclerotic stenosis in the coronary, renal, and iliofemoral circulations. The technique of cerebral angioplasty is different from that used to treat atherosclerotic disease in that angioplasty balloons used for vasospasm are more compliant and are easily ruptured if the manufacturer's recommended volume is exceeded. ${ }^{52}$ Many years passed before balloon angioplasty was attempted as a therapy for cerebral vasospasm because it was thought that the vasospasm was secondary to sustained muscular contraction and that mechanical dilation of the cerebral arteries would be a transient and illogical solution. ${ }^{39}$ In 1984, Zubkov and colleagues ${ }^{63}$ reported the first use of transluminal balloon angioplasty for vasospasm after aneurysmal SAH.

\section{Mechanism of Action}

Transluminal balloon angioplasty can be used on the more proximal vessels as a means to dilate vasospastic portions. This technique has size limitations, however, and cannot be used to reach the smaller peripheral arteries. It is unclear what long-term effect balloon dilation has on the vasculature, but histological studies have shown that there are microscopic differences between the vasospastic vessels treated with balloon angioplasty and untreated vessels. ${ }^{6,62}$ Vasospastic vessels that were not treated exhibited a proliferation of connective tissue in the intima and media. In contrast, vessels treated with balloon angioplasty exhibited compression and stretching of the arterial walls (smooth muscle, connective tissue, and internal elastic lamina) without damage to or disruption of the cellular or connective tissue elements.

\section{Technique of Administration}

A CT scan is usually performed before endovascular therapy is initiated to rule out the presence of intracranial hemorrhage, recent large infarction, or hydrocephalus. Transluminal balloon angioplasty is performed via a transfemoral approach and is limited only by the expertise of the endovascular neurosurgeon or interventional radiologist. A digital subtraction angiography study is first performed to elucidate whether the findings for affected vasospastic vessels can explain the neurological deficits., $5,13,17$ If deemed appropriate, a No. 5 French (or larger) sheath is placed in the femoral artery (if this has not already been done), followed by placement of a guidewire into the cerebral circulation. Heparin may be used in many cases, but this decision is based on the clinical picture and the discretion of the interventionalist. Angioplasty is then performed using a silicone microballoon. Eskridge, et al., ${ }^{13}$ performed successive gradual mechanical dilations of the vessel lumen in a four-step sequence (25\% inflation, then $50 \%$ inflation, then $75 \%$ inflation, then $100 \%$ inflation), with intermittent deflations. Firlik, et al., ${ }^{17}$ calculated the degree of balloon inflation so that it was proportional to the normal size of the vessel being dilated. Intraarterial infusion of papaverine may be used as an adjunct therapy to facilitate introduction of the balloon catheter into the vasospastic vessel. ${ }^{12,13,39}$ Care is taken not to overinflate the artery past its original diameter to avoid vessel rupture. ${ }^{39}$

\section{Clinical Effects and Outcomes}

The effect of transluminal balloon angioplasty has been assessed by evaluating many different variables, including neurological improvement, angiographic changes, TCD studies, and CBF measurements. Many authors have reported sustained clinical improvement and reversal of delayed ischemic neurological deficits, with treatment efficacy ranging anywhere from 11 to $92 \%$. $5,13,17,18,38,39,44,55,63$ In a review of the literature, Hoh and Ogilvy ${ }^{23}$ reported clinical improvement in $328(62 \%)$ of 530 patients treated with balloon angioplasty. Some reports show that favorable results can be achieved when angioplasty is initiated early after the onset of clinical vasospasm. ${ }^{12,13,48}$ Rosenwasser, et al., reported sustained clinical improvement when patients were treated within 2 hours after development of clinical vasospasm. Bejjani, et al., ${ }^{5}$ showed that clinical improvement was more marked when the interval from clinical deterioration to angioplasty treatment was less than 24 hours. Eskridge, et al., ${ }^{13}$ recommended initiating angioplasty treatment within 12 hours of the onset of symptoms because the vessel becomes more fibrotic and technically more challenging to dilate if it has been in spasm for a longer period.

Improvement in angiographic vasospasm is frequently observed after angioplasty. ${ }^{18}$ Firlik, et al., ${ }^{17}$ noted $100 \%$ angiographic improvement in all 13 patients who underwent balloon angioplasty. Murai, et al., ${ }^{38}$ noted $100 \%$ angiographic improvement in all 12 of their patients, in whom 19 vascular territories were treated. Although balloon angioplasty improves the caliber of the vasospastic vessel, the efficacy of treatment is better defined by the clinical outcomes and CBF measurements.

The TCD measurements obtained after angioplasty can be compared with pretreatment baseline values to assess the efficacy of the procedure. Newell, et al., ${ }^{40}$ showed decreased TCD ultrasonography flow velocities in 27 (93\%) of 29 patients after angioplasty. Polin, et al., ${ }^{44}$ noted that in $15(39 \%)$ of 38 patients, improved TCD velocities were demonstrated after angioplasty. Hoh and Ogilvy ${ }^{23}$ found a mean improvement of $69 \%$ in TCD velocities. The TCD information is limited in that these data do not provide information about more distal vasculature beyond the window of insonation and they do not accurately determine regional CBF and potential ischemia. ${ }^{17}$

Measurements of CBF have been performed using magnetic resonance imaging (diffusion-weighted or perfusion-weighted), Xe-CT, positron emission tomography, or single-photon emission computed tomography scanning as a means to evaluate angioplasty therapy. Improvements in CBF after balloon angioplasty have ranged from 60 to $100 \%$. $12,17,18,40,42$ Firlik, et al., reported improvement in $\mathrm{CBF}$ on Xe-CT, with all 12 of their patients demonstrating improvement in mean CBF (from $13 \pm 2.1 \mathrm{ml} / 100 \mathrm{~g} / \mathrm{min}$ to $44 \pm 13.1 \mathrm{ml} / 100 \mathrm{~g} / \mathrm{min}$ ) in the regions of interest at risk of infarction. Angioplasty also significantly decreased the mean number of regions of interest at risk of infarction in all patients. Hoh and Ogilvy ${ }^{23}$ reported an overall improvement in CBF in 92 $(85 \%)$ of 108 patients in their review of a group who had undergone angioplasty since 1985 . However, Murai, et al. ${ }^{38}$ noted no significant influence on CBF after balloon angioplasty. At the 3-week follow-up visit, global CBF was $35.1 \pm 8.2 \mathrm{ml} / 100 \mathrm{~g} / \mathrm{min}$, with CBF on the side treated with angioplasty $(37.8 \pm 10.3 \mathrm{ml} / 100 \mathrm{~g} / \mathrm{min})$ essentially the same as that on the other side. 


\section{Endovascular therapies for cerebral vasospasm after aneurysmal SAH}

Angioplasty effectively reverses vasospasm in large, proximal cerebral vessels but has limited ability to reach small, distal vessels such as the distal MCA or sharply angled vessels such as the ACA, both of which are accessible with intraarterial papaverine. When angioplasty and intraarterial papaverine were compared, Elliott, et al., ${ }^{12}$ found balloon angioplasty to be superior to papaverine infusion in decreasing velocities measured by TCD ( 45
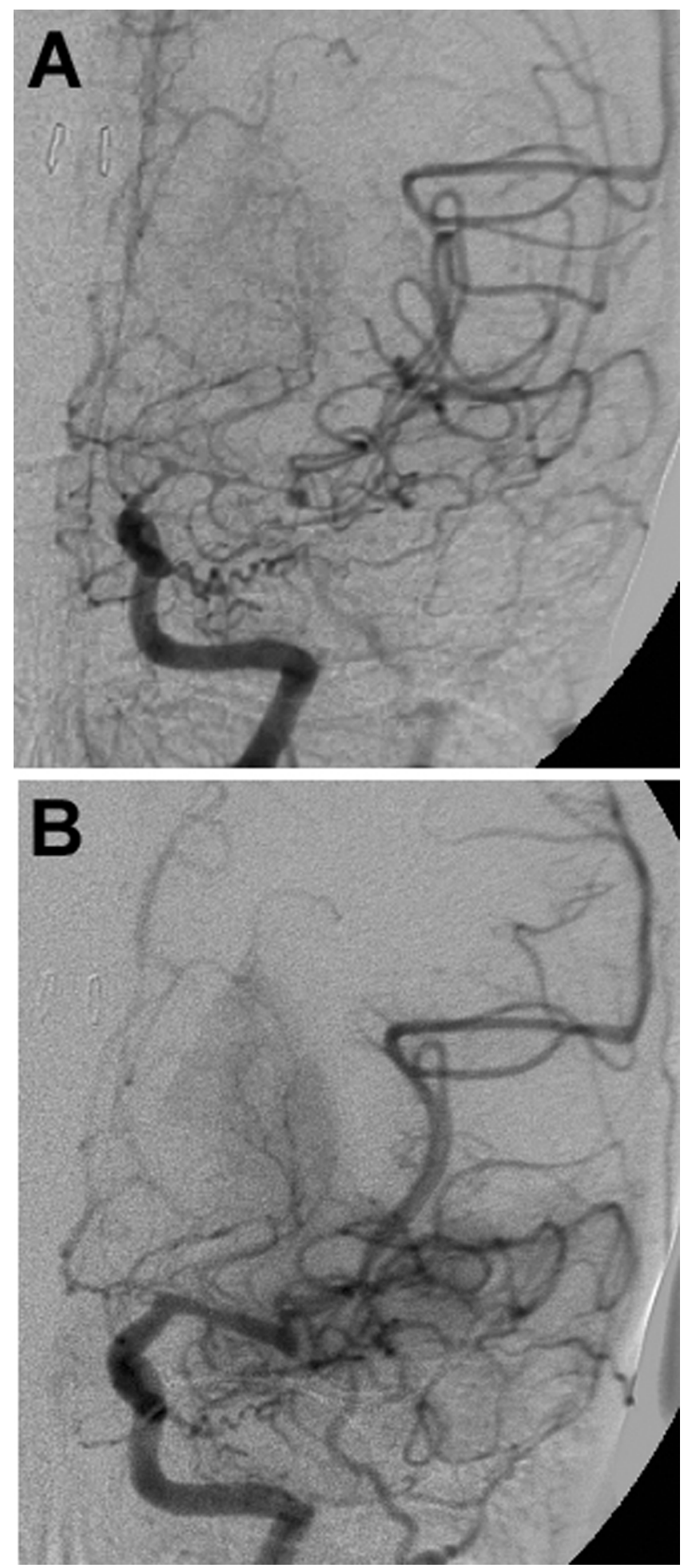

compared with $20 \%$ mean decrease, respectively). The effects of angioplasty were more sustained and thus required fewer multiple treatments than papaverine (one compared with 10). Despite these differences, some authors have advocated the integration of balloon angioplasty and intraarterial papaverine as complementary rather than alternative techniques (Fig. 1). ${ }^{50}$ Oskouian, et al. ${ }^{42}$ demonstrated a significant increase in CBF, from 33.3 to $41.7 \mathrm{ml} / 100 \mathrm{~g} / \mathrm{min}$, in 13 patients who received combined therapy. The TCD velocities decreased from 148.9 to $111.4 \mathrm{~cm} / \mathrm{second}$, with a mean increase in vessel diameter of $42.2 \%$.

\section{Treatment-Related Complications}

The rate of major procedure-related complications was estimated to be $5 \%$ and the incidence of vessel rupture was $1.1 \%$, according to the review by Hoh and Ogilvy. ${ }^{23}$ Some reported complications include thromboembolism, arterial dissection, reperfusion hemorrhage, branch occlusion, bleeding from untreated aneurysms, retroperitoneal hematoma, groin hematoma at the catheter site, and vessel rupture. $5,13,17,18,23,38,39,44,55,63$

\section{Intraarterial Papaverine}

Intraarterial papaverine is the most researched pharmacological agent for treatment of cerebral vasospasm, and it has been widely used since initial studies were described in 1992 by Kaku, et al. ${ }^{26}$ and Kassell, et al. ${ }^{27}$ It has been used with some success to treat angiographic and clinical vasospasm (Fig. 2), and it may be administered alone or in combination with transluminal balloon angioplasty. $8,26,27,33,34,42$ Because papaverine is a potent vasodilator of the proximal, intermediate, and distal cerebral arteries, its use may be advantageous in treating diffuse nonfocal vasospasm and distal vasospastic vessels that are inaccessible by balloon angioplasty techniques. Papaverine may also be administered as an adjunct to dilate vessels and facilitate placement of the balloon catheter for angioplasty. Some of the major disadvantages of papaverine are its transient effects, resulting in recurrent vasospasm, the need for multiple treatments, and the risk of increased ICP. ${ }^{26,33,42}$ Because of these limitations, more centers are using alternative intraarterial pharmacological agents that are longer lasting and have fewer ICP complications.

\section{Mechanism of Action}

Papaverine is a benzylisoquinolone alkaloid derived

FIG. 1. A: Left ICA angiogram obtained in a patient in whom severe vasospasm developed in the left supraclinoid ICA, $A_{1}$ and $M_{1}$ segments, 6 days after clip occlusion of an anterior communicating artery aneurysm. B: Left ICA angiogram obtained after combination therapy with intraarterial papaverine and balloon angioplasty, demonstrating marked improvement in the left supraclinoid ICA and $M_{1}$ segments. Access to the left $A_{1}$ segment for angioplasty could not be gained, and it remained severely narrowed despite papaverine infusion. (Reprinted with permission from Liu JK, Couldwell WT: Intra-arterial papaverine infusions for the treatment of cerebral vasospasm induced by aneurysmal subarachnoid hemorrhage. Neurocrit Care 2: 124-132, 2005.) 
from opium and is known to be a potent vasodilator. Its mechanism of action is thought to arise from inhibition of cAMP and cGMP phosphodiesterases in smooth muscle, leading to increased intracellular levels of cAMP and cGMP. In addition, papaverine may inhibit the release of calcium from the intracellular space by blocking calcium ion channels in the cell membrane. ${ }^{39}$ In canine vasospasm models, papaverine was noted to have an effective halflife of less than 1 hour. ${ }^{33,59}$ Although the actual effective half-life of smooth-muscle relaxation has not been determined in human cerebral arteries, some evidence indicates that plasma levels of papaverine rise with continuous administration of the agent every 6 hours, suggesting a true half-life closer to 24 hours. ${ }^{9}$

\section{Technique of Administration}

Papaverine $\mathrm{HCl}$ is available in a $3 \%$ concentration (30 $\mathrm{mg} / \mathrm{ml}$ ) at $\mathrm{pH} 3.3$. For preparation, $300 \mathrm{mg}$ of papaverine is diluted in $100 \mathrm{ml}$ of normal saline to obtain a concentration of $0.3 \% .^{33}$ Papaverine should not be mixed with contrast agents or heparin because it may cause precipitation of crystals. ${ }^{42}$ Sawada, et al., ${ }^{49}$ noted that infusion of highly concentrated papaverine may have fewer vasodilatory effects and a higher risk of temporary deterioration, possibly because of emboli formed from papaverine precipitates. Intraarterial papaverine can be infused into the ACA and MCA simultaneously by placing the microcatheter tip into the supraclinoid segment of the ICA just above the ophthalmic artery branch point.

Alternatively, superselective infusions into either the ACA or MCA territory can be performed; this strategy may be important in some cases to ensure adequate delivery of papaverine to the target territory. For posterior circulation vasospasm, the microcatheter tip is positioned just below the affected area. Once the catheter is placed in the appropriate vascular territory of vasospasm, the 300-mg dose is generally administered at a rate of $3 \mathrm{ml} /$ minute. It is important to monitor the patient's blood pressure, ICP, and neurological status during the papaverine infusion. Treatment should be discontinued immediately if there is drop in blood pressure, increased ICP, or worsening neurological status. Most of these changes resolve after cessation of papaverine infusion. A slower infusion may reduce the risk that these complications could develop.

\section{Clinical Effects and Outcomes}

The clinical benefit of intraarterial papaverine infusion has been variable; results have ranged from 0 to $100 \%$ improvement. ${ }^{8,10,12,14,17,26,27,34,35,42,45,46,49,58}$ Liu, et al. ${ }^{34}$ reported clinical improvement in $12(71 \%)$ of 17 patients; eight patients had improvement of depressed level of consciousness, one had reversal of upper-extremity weakness, and three had improvement of vasospasm-induced aphasia. In a review of the literature by Hoh and Ogilvy, ${ }^{23}$ clinical improvement after papaverine infusion was demonstrated in $148(43 \%)$ of 346 patients. Poor clinical outcome is more likely in elderly patients or in those presenting with a poor clinical status at the onset of SAH. ${ }^{46}$ Although many anecdotal and retrospective reports in the literature have documented improved neurological outcomes after intraarterial papaverine, findings in studies of its clinical
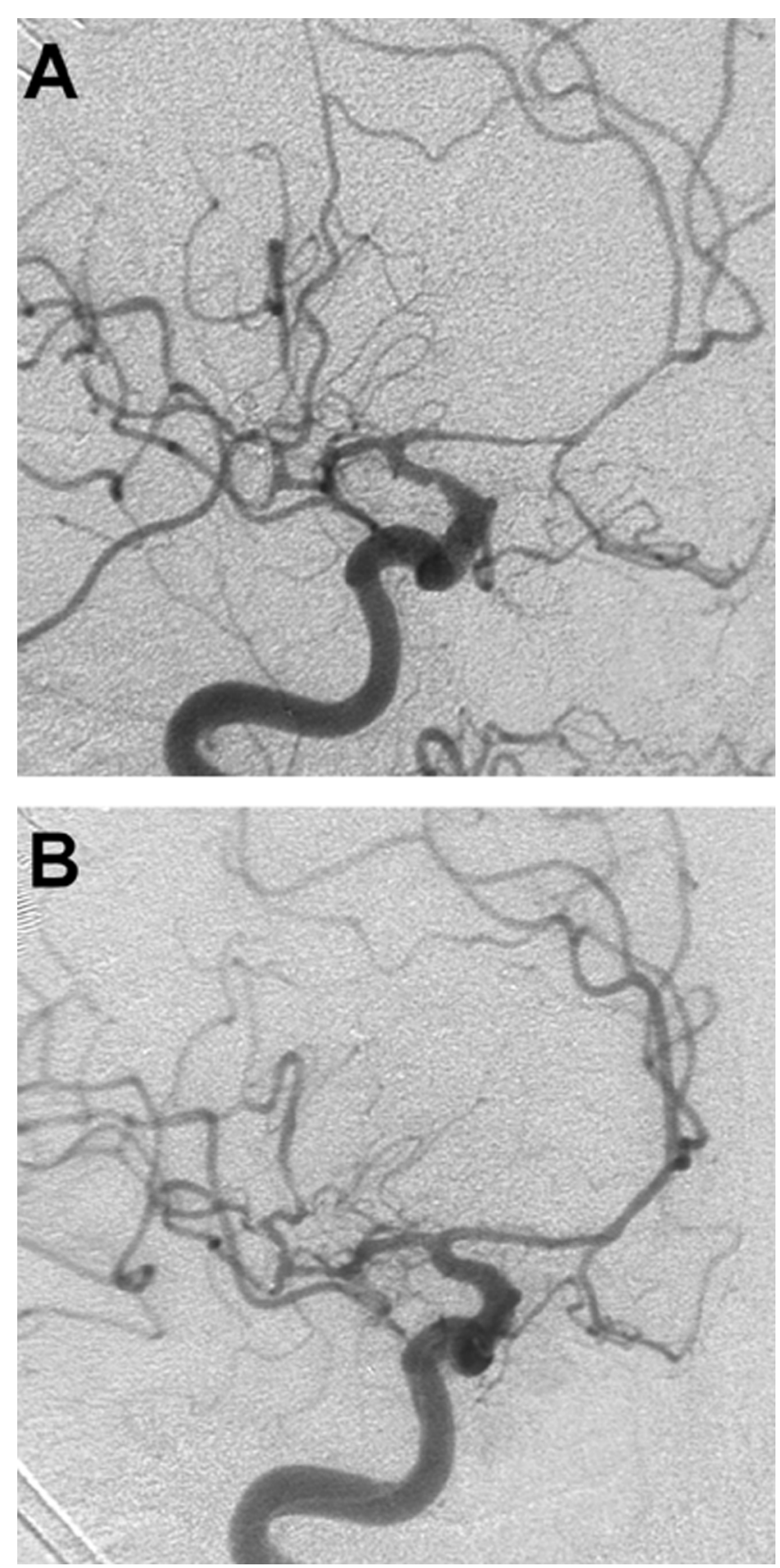

FIG. 2. A: Right ICA angiogram demonstrating significant vasospasm of the supraclinoid ICA, $\mathrm{M}_{1}, \mathrm{~A}_{1}$, and $\mathrm{A}_{2}$ segments, in a patient in whom left-sided weakness and worsening mental status developed 9 days after clip occlusion of a right MCA aneurysm. B: Right ICA angiogram obtained after supraclinoid infusion of intraarterial papaverine, demonstrating marked improvement of angiographic vasospasm. (Reprinted with permission from Liu JK, Couldwell WT: Intra-arterial papaverine infusions for the treatment of cerebral vasospasm induced by aneurysmal subarachnoid hemorrhage. Neurocrit Care 2: 124-132, 2005.)

efficacy remain inconclusive and its precise role in treating vasospasm has yet to be determined in controlled prospective randomized trials. ${ }^{45}$

Intraarterial papaverine has been noted to be effective in increasing angiographically demonstrated vessel diame- 
ter; $;, 37$ to improve CBF by dilating the proximal, intermediate, and distal cerebral arteries; ${ }^{8}$ to improve mean cerebral circulation time; ${ }^{34,36}$ and to improve cerebral oxygenation. ${ }^{14}$ In a study by Oskouian, et al. ${ }^{42}$ intraarterial papaverine infusions increased vessel diameter in 20 patients by an average of $30.1 \%$. This correlated with an increased $\mathrm{CBF}$ in $11(55 \%)$ of 20 patients and a decrease in MCA velocity measured using TCD ultrasonography in $17(85 \%)$ of 20 patients. Vessels with more vasospasm and narrower lumens have been shown to respond to papaverine treatment with greater increases in vessel diameter. ${ }^{37}$ The degree of arterial responsiveness, however, was independent of the post-SAH day of treatment.

Cerebral circulation time can be calculated from conventional angiograms to assess regional $\mathrm{CBF}$ after papaverine treatment. There is an inverse relationship between regional $\mathrm{CBF}$ and cerebral circulation time; ${ }^{41}$ thus it is postulated that a prolonged circulation time may correlate with a decreased CBF. ${ }^{33}$ Milburn, et al., ${ }^{36}$ showed a decrease in cerebral circulation time after intraarterial papaverine infusions in 58 of 59 carotid territories in 27 patients. Liu, et al. ${ }^{34}$ demonstrated that patients with clinical vasospasm exhibited a prolonged cerebral circulation time compared with a control group of patients without vasospasm. They also showed that intraarterial papaverine treatments decreased the mean cerebral circulation time from 6.54 to 4.19 seconds ( $p<0.001,36 \%$ decrease). This decrease in the cerebral circulation time was likely associated with improvements in CBF. In cases of recurrent vasospasm, repeated papaverine infusions consistently improved the cerebral circulation time with a similar magnitude of change (mean change 2.06 seconds), which demonstrates its effectiveness in previously treated vessels.

Cerebral oxygenation has also been found to improve after intraarterial papaverine infusion. Fandino, et al., ${ }^{14}$ evaluated cerebral arteriovenous oxygen and lactate differences by using continuous monitoring of jugular bulb venous oxygen saturation. Of the 10 patients evaluated, $100 \%$ showed major improvement in jugular bulb oxygen saturation after intraarterial papaverine treatment. In three patients in whom evidence of lactic acidosis was found before papaverine treatment, normalization of lactate concentration in the jugular bulb had occurred within 4 hours of treatment.

\section{Treatment-Related Complications}

The overall complication rate from papaverine infusion was estimated to be $9.9 \%{ }^{23}$ One of the most serious complications of intraarterial papaverine is a rapid increase in ICP. ${ }^{35}$ This may be attributed to the postinfusion increase in CBF and cerebral blood volume from cerebral vasodilation. ${ }^{10,35}$ Thus, ICP monitoring with an external ventricular drain or a fiberoptic catheter is recommended. Other reported complications include thrombocytopenia, hypotension, seizures, transient neurological deficits (mydriasis and brainstem depression), monocular blindness, precipitation of papaverine crystal emboli during infusion, and paradoxical worsening of vasospasm leading to cerebral infarction. . $^{10,33,35,57}$ Cross, et al., studied 28 patients and found that those with a baseline ICP lower than $15 \mathrm{~mm} \mathrm{Hg}$ were less likely to have significant increases in ICP during treatment than those with a baseline ICP higher than 15 $\mathrm{mm} \mathrm{Hg}$. Also, patients with an ICP increase of more than $10 \mathrm{~mm} \mathrm{Hg}$ during infusion were more likely to experience adverse clinical events (such as mental status changes, seizures, transient aphasia, agitation, and hypotension). Treatment should be terminated if the patient experiences any of these papaverine-induced complications. With slower infusions these adverse effects may be avoided.

\section{Intraarterial Nimodipine}

Nimodipine has been studied in the past as a prophylactic oral or intravenous treatment for reducing cerebral vasospasm and cerebral infarction as well as improving outcomes after SAH. Among the calcium channel antagonists, nimodipine alone was found to improve the overall outcome within 3 months of aneurysmal SAH. All calcium channel antagonists were found to prevent secondary ischemia after $\mathrm{SAH} .{ }^{15,43}$ Nimodipine is often given orally as a standard treatment in patients with $\mathrm{SAH}$; however, when nimodipine cannot be taken by mouth, continuous intravenous administration of calcium antagonists for 7 to 10 days is recommended. ${ }^{15}$ In more recent studies, nimodipine has been applied intraarterially for the treatment of refractory cerebral vasospasm. ${ }^{7,24}$

\section{Mechanism of Action}

Nimodipine is a dihydropyridine calcium antagonist that reduces the influx of calcium through the L-type calcium channels in smooth-muscle cells. This leads to decreased smooth-muscle contraction as well as decreased release of vasoactive substances from the endothelium, resulting in reduced arterial narrowing. Nimodipine may also have some direct neuroprotective properties, including blockage of free-radical attack on the intraneuronal mitochondria, improvement of carbon dioxide reactivity and cerebral oxygen metabolism, or reduction of tissue damage caused by calcium overload in ischemic neurons. ${ }^{7,15,47}$

\section{Technique of Administration}

The presence of a local effect of alcohol must be considered because ethyl alcohol is an excipient used by the manufacturer of commercially available nimodipine. ${ }^{7}$ A 1- to 3-mg dose of nimodipine is diluted with 15 to $45 \mathrm{ml}$ of normal saline to obtain a $25 \%$ dilution, which is infused at a slow continuous rate over 10 to 30 minutes $(\sim 0.1$ $\mathrm{mg} / \mathrm{minute}$ ) into the desired vascular territory via a transfemoral approach. The total dose injected is determined based on the degree of initial vasospasm, the degree of vessel dilation, and initial blood pressure. A repeated dose may be used if no angiographic improvement is seen after 15 to 20 minutes. ${ }^{24}$ The total dose that has been used in cases reported in the literature has never been greater than $5 \mathrm{mg}$ per procedure. Vascular injury from the alcohol has never been reported. Blood pressure, ICP, and neurological examination should be monitored during nimodipine infusions.

\section{Clinical Effects and Outcomes}

Intraarterial infusion of nimodipine has only been tested recently. Biondi, et al., ${ }^{7}$ retrospectively reviewed 25 patients in whom nimodipine was administered intraarterially in the ICA or VA to treat symptomatic cerebral vasospasm, 
for a total of 30 procedures. Substantial and stable clinical improvement was reported in 19 of 25 patients (76\%) within 24 hours of treatment. Angiographic dilation was observed in 13 (43\%) of 30 procedures. Three of four patients who required multiple infusions showed clinical improvement. After 3 to 6 months, 18 (72\%) of 25 patients had a favorable outcome. There were no clinically evident complications (worsening vasospasm, prolonged hypotension, worsening ICP) or deaths. Mild transient drops in systolic blood pressure (range 10-40 mm $\mathrm{Hg}$; mean 18 $\mathrm{mm} \mathrm{Hg})$ were observed after $26(87 \%)$ of 30 infusion treatments, but systolic blood pressure never fell below $100 \mathrm{~mm} \mathrm{Hg}$. Blood pressure normalized within 5 to 10 minutes after treatment.

Hui and $\mathrm{Lau}^{24}$ retrospectively reviewed nine patients who underwent intraarterial nimodipine infusion, and these authors observed a mean increase in vessel diameter of $66.6 \%$. Recurrent vasospasm occurred in one patient, who subsequently received a second treatment and showed good neurological improvement. Immediate clinical improvement in either the level of consciousness or focal neurological deficit was seen in eight $(89 \%)$ of the nine patients and was sustained in seven (78\%) of the nine. No significant decreases in blood pressure or heart rate were observed in any of the patients. Overall, both retrospective studies have shown intraarterial nimodipine to be relatively safe, with a low risk of adverse effects. Nevertheless, further studies in the form of prospective randomized trials with CBF measurements are warranted to establish the efficacy of intraarterial nimodipine.

\section{Treatment-Related Complications}

Some of the main systemic complications of nimodipine in general are hypotension, bradycardia, rash, and diarrhea. Neither Biondi, et al., ${ }^{7}$ nor Hui and $\mathrm{Lau}^{24}$ reported significant changes in blood pressure, heart rate, or ICP after nimodipine infusion. One patient experienced a run of ventricular ectopic beats in the course of 10 to $15 \mathrm{sec}-$ onds, but it was unclear whether this was directly related to nimodipine infusion or if it was an incidental finding.

\section{Intraarterial Nicardipine}

Initially, nicardipine was studied as a prophylactic intravenous agent intended for use in the prevention of cerebral vasospasm after SAH. Haley and colleagues ${ }^{19-21}$ found that intravenous nicardipine was beneficial in lowering the incidence of angiographic, symptomatic, and TCD-confirmed vasospasm. They also discovered that low-dose was as effective as high-dose intravenous nicardipine and had fewer side effects. It was not until recently that intraarterial nicardipine has been tried as a form of endovascular treatment for refractory cerebral vasospasm. ${ }^{4}$ Kasuya, et al., ${ }^{29}$ studied pellet-sized nicardipine prolonged-release implants placed adjacent to arteries during aneurysm clip placement surgery and found that the pellets completely prevented angiographic vasospasm.

\section{Mechanism of Action}

Nicardipine is a dihydropyridine calcium channel antagonist with more selective effects on vascular smooth muscle than on cardiac muscle. It possesses pharmacological activity that is virtually equivalent to that of nimodipine, in that it reduces the influx of calcium through the L-type calcium channels in smooth-muscle cells. One advantage over nimodipine is that nicardipine is available for parenteral administration in North America.

\section{Technique of Administration}

Intraarterial nicardipine has been administered to the appropriate vessels through a microcatheter inserted via a transfemoral approach. In the study by Badjatia, et al., ${ }^{4}$ nicardipine was diluted with physiological saline to a concentration of $0.1 \mathrm{mg} / \mathrm{ml}$ and administered in 1-ml aliquots to a maximum dose of $5 \mathrm{mg}$ per vessel. Dosages were derived from an accepted intravenous bolus-dosing schedule used for the treatment of hypertension, and from observation of the agent's angiographic effect. Ventriculostomies were made in all patients to monitor ICP and drain cerebrospinal fluid if substantial increases in ICP occurred.

\section{Clinical Effects and Outcomes}

Badjatia, et al., ${ }^{4}$ applied monotherapy with intraarterial nicardipine in 18 patients; a total of 38 vessels were treated. They found an immediate angiographically confirmed dilation, and TCD ultrasonography studies revealed improvement in all vessels after intraarterial nicardipine treatment. Four days after treatment, the mean TCD velocities had improved significantly, from $268.9 \pm 77.8 \mathrm{~cm} /$ second to $197.6 \pm 74.1 \mathrm{~cm} / \mathrm{second}$. Clinical neurological improvement was reported in $42 \%$ of posttreatment neurological examinations. Only one patient received an additional treatment, from which we infer that nicardipine may have a more sustained effect than papaverine.

\section{Treatment-Related Complications}

Although complications such as prolonged hypotension, pulmonary edema, and renal dysfunction have been reported after intravenous delivery of nicardipine, these did not occur with intraarterial nicardipine. The main adverse effect reported in the study by Badjatia, et al., ${ }^{4}$ was an increase in ICP in six (33\%) of 18 patients. In five of these patients, the ICP returned to baseline after the ventriculostomy was opened. One patient did not respond to ventricular drainage and suffered a sustained increase in ICP that was treated with mannitol. However, this patient had an intracranial hematoma and only tenuous control of ICP had been achieved before nicardipine therapy was initiated.

\section{Intraarterial Verapamil}

Verapamil has been widely used in the past to treat coronary vasospasm. The coronary arteries are similar in size to the cerebral arteries, so it was thought that the cerebral arteries might have a similar response to verapamil, with the prospect of preventing ischemia caused by cerebral vasospasm. Joshi, et al. ${ }^{25}$ noted an increase in CBF in patients undergoing ICA balloon test occlusion after verapamil administration. Verapamil has also been used successfully to prevent catheter-induced vasospasm after placement of guiding catheters and before insertion of microcatheters for balloon angioplasty. ${ }^{16}$ 

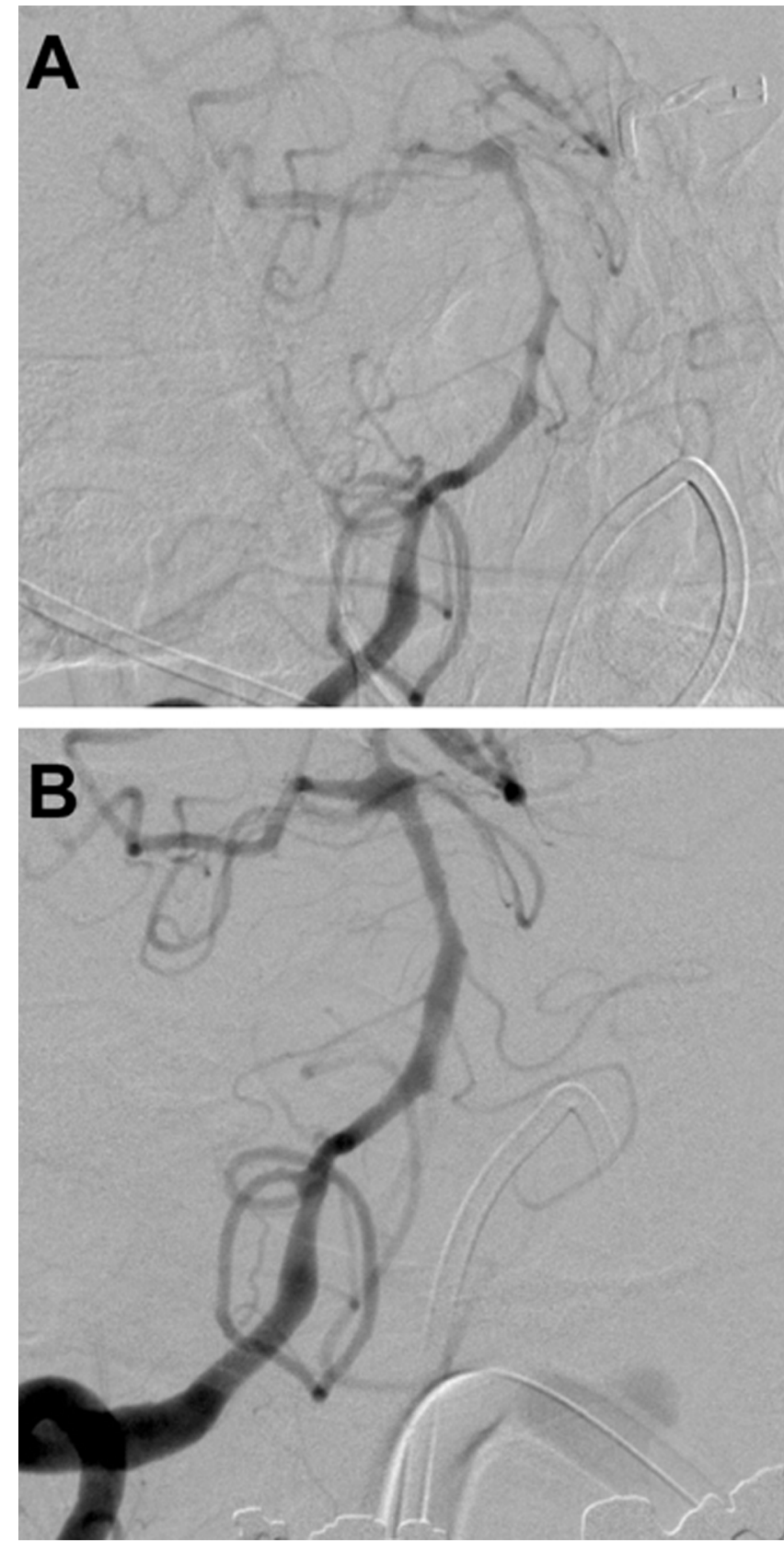

FIG. 3. A: Right VA angiogram demonstrating severe vasospasm of the basilar artery in a patient in whom worsening mental status developed 5 days after clipping of a left ICA aneurysm. B: Right VA angiogram obtained after infusion of intraarterial verapamil, demonstrating significant improvement of vasospasm.

\section{Mechanism of Action}

Verapamil is an injectable phenylalkylamine calcium channel blocker whose mechanism of action is similar to that of nimodipine. It reduces the influx of calcium through the L-type calcium channels in smooth-muscle cells, thus enabling vasodilation. Verapamil has also been known to decrease electrical conduction in the heart and to slow the heart rate.

\section{Technique of Administration}

Feng, et al. ${ }^{16}$ administered intraarterial verapamil in three settings: 1) before balloon angioplasty, to prevent vasospasm; 2) for treatment of mild vasospasm that did not warrant angioplasty; or 3) for treatment of moderate vasospasm that could not be safely treated with angioplasty (Fig. 3). When intraarterial verapamil was used in the first setting, a No. 6 French guiding catheter was inserted via a transfemoral approach into the ICA or VA, and a 1 - to $2-\mathrm{mg}$ bolus of verapamil was then infused before introduction of the balloon catheter. For treatment of mild vasospasm (the second setting), a No. 5 French diagnostic catheter was delivered transfemorally into the ICA or VA after angiography, followed by a 2-mg bolus of intraarterial verapamil. In the third scenario, verapamil was used alone for moderate to severe vasospasm, and thus higher doses tended to be given. The mean dose was $3 \mathrm{mg}$ per patient and the mean dose per vessel was $2 \mathrm{mg}$.

\section{Clinical Effects and Outcomes}

In the retrospective study by Feng, et al. ${ }^{16} 29$ patients received intraarterial verapamil for treatment of refractory cerebral vasospasm, for a total of 34 procedures. Intraarterial verapamil was used in one of the three settings noted previously. When verapamil was used alone, neurological improvement was recorded in five (29\%) of 17 procedures. Angiographic studies performed on 10 occasions revealed a $44 \pm 9 \%$ increase in vessel diameter. The most dramatic effects were seen in patients with severe vasospasm. Intraarterial verapamil appeared to dilate the distal cerebral vasculature. Although these improvements in the results of neurological examination and angiographic findings are encouraging, larger prospective studies need to be conducted to evaluate the true efficacy of intraarterial verapamil.

\section{Treatment-Related Complications}

Some major complications of intravenous verapamil are hypotension and bradycardia; however, there were no significant decreases in mean arterial pressure or changes in heart rate reported in the study of intraarterial verapamil. ${ }^{16}$ There were no dramatic or prolonged increases in ICP, nor were any secondary signs of increased ICP (bradycardia or sudden rise in blood pressure) noted. Overall, intraarterial verapamil administration had very few systemic effects.

\section{Intraarterial Milrinone}

Milrinone is primarily used to treat patients with acute and chronic heart failure; however, it has been studied in the past decade or so for the prevention of cerebral vasospasm in both canines and humans, with promising results. It has been used in intravenous preparations $\mathrm{s}^{30}$ and cisternal irrigation ${ }^{2}$ as well as intraarterially. ${ }^{1}$ In doublehemorrhage canine models of vasospasm, intravenous milrinone was administered and found to be effective in preventing chronic cerebral vasospasm. ${ }^{30}$ When milrinone was continuously infused at $30 \mathrm{ml} /$ hour into the supratentorial cisternal space, lateral ventricle, or spinal subarachnoid space, it reduced the incidence of vasospasm compared with conventional therapy. ${ }^{2}$ 


\section{Mechanism of Action}

Milrinone is a bypyridine methyl carbonitrile analog of amrinone. Its mechanism of action is similar to that of papaverine, which is a nonselective inhibitor of phosphodiesterase. Milrinone works as an inotropic drug and a vasodilator (an "inodilator") by selective inhibition of cAMP-specific phosphodiesterase III in both cardiac and vascular smooth muscle. It has been shown in experimental studies to be 10 to 30 times more potent than amrinone (its parent compound), and it has fewer side effects. ${ }^{2}$

\section{Technique of Administration}

In the study by Arakawa, et al., ${ }^{1}$ the patient underwent induction of local anesthesia and a No. 2.3 or 4 French microcatheter was threaded just proximal to the site of intracranial vasospasm via a transfemoral route. Milrinone was diluted with $0.9 \% \mathrm{NaCl}$ to a $25 \%$ concentration level. This mixture was then infused at a rate of $1 \mathrm{ml} /$ minute to a total dose of 5 to $15 \mathrm{mg}$. The actual dose infused depended on the amount of dilation of the spastic vessel during infusion. Because the drug's pharmacological half-life is approximately 50 minutes, parenteral milrinone was administered after intraarterial milrinone for up to 2 weeks post-SAH to see whether this was useful in preventing recurrent vasospasm.

\section{Clinical Effects and Outcomes}

In a prospective study of seven patients with refractory cerebral vasospasm after SAH, Arakawa, et al., ${ }^{1}$ delivered intraarterial milrinone, followed by its intravenous administration, to evaluate angiographic dilation and changes in the rate of CBF. They discovered statistically significant angiographic dilation in all seven patients. The mean MCA diameter was $1.29 \pm 0.48 \mathrm{~mm}$ in the $\mathrm{M}_{1}$ segment and $0.83 \pm 0.24 \mathrm{~mm}$ in the $\mathrm{M}_{2}$ segment before intraarterial milrinone treatment. After treatment, the mean MCA diameter was $1.83 \pm 0.46 \mathrm{~mm}$ in the $\mathrm{M}_{1}$ segment and 1.49 $\pm 0.25 \mathrm{~mm}$ in the $\mathrm{M}_{2}$ segment. The CBF was measured using hexamethylpropyleneamine contrast material for single-photon emission computed tomography, and was found to increase significantly, from $32.5 \pm 3.5 \mathrm{ml} / 100$ $\mathrm{g} / \mathrm{min}$ before to $39.3 \pm 3.3 \mathrm{ml} / 100 \mathrm{~g} / \mathrm{min}$ after intraarterial milrinone treatment. Four of the seven patients who received subsequent intravenously delivered milrinone did not experience recurrent vasospasm, whereas the other three patients required repeated treatment with intraarterial milrinone.

Amrinone, the parent compound of milrinone, has also been used in endovascular therapy for refractory cerebral vasospasm. In two cases reported by Yoshida, et al., ${ }^{61}$ in which intraarterial amrinone was used, the authors noted resolution of persistent vasospasm that occurred after earlier endovascular treatment with intraarterial papaverine.

\section{Treatment-Related Complications}

Parenteral milrinone delivered in large doses can cause systemic hypotension. Arakawa, et al., ${ }^{1}$ found no significant changes in the mean heart rate or blood pressure in their patients. Recurrence of symptomatic vasospasm was found in three of seven patients, despite subsequent continuous intravenous infusion of milrinone. These patients were successfully treated with either a second or third trial of intraarterial milrinone. There was no mention of ICP monitoring in this study.

\section{Intraarterial Fasudil}

Intravenous fasudil has been found to reduce significantly the incidence of both symptomatic and asymptomatic cerebral vasospasm after aneurysmal SAH in a prospective double-blind study conducted by Shibuya, et al., ${ }^{51}$ in 1992. Since then, two studies have been reported in the literature on intraarterial fasudil administration for the treatment of cerebral vasospasm..$^{52,55}$

\section{Mechanism of Action}

Fasudil is a unique drug with more than one mechanism of action that enables it to be used as treatment for cerebral vasospasm. It is a protein kinase inhibitor and functions as a potent vasodilator. It inhibits enzymes such as myosin light-chain kinase and protein kinase $\mathrm{C}$ in a manner relatively specific for cerebral vasculature. ${ }^{54}$ Fasudil and its active metabolite hydroxyfasudil both also inhibit Rho kinase, which has been implicated in the development of cerebral vasospasm. ${ }^{56}$ Fasudil is also an intracellular calcium ion inhibitor.

\section{Technique of Administration}

Thirty milligrams of fasudil hydrochloride are dissolved in $20 \mathrm{mg}$ physiological saline, and a total dose ranging from 15 to $45 \mathrm{mg}$ of solution is infused transfemorally at a rate of $1.5 \mathrm{mg} /$ minute into the desired vascular territory. Neurological status, vital signs, and ICP are usually monitored throughout the procedure.

\section{Clinical Effects and Outcomes}

In 1999, Tachibana, et al., ${ }^{54}$ reported the first study of intraarterial administration of fasudil, which included 10 patients. All had angiographic vasospasm, and three presented with clinical vasospasm as well. A total of 24 territories were treated, with angiographic improvement noted in 16 vessels $(66.7 \%)$. Nine $(90 \%)$ of 10 patients demonstrated angiographic improvement of vasospasm. In two $(66.7 \%)$ of the three who presented with clinical vasospasm, their neurological symptoms resolved without sequelae. The investigators concluded that intraarterial fasudil is safe and effective for treatment of cerebral vasospasm; however, further prospective clinical trials are warranted to support their initial findings.

A later study by Tanaka, et al., ${ }^{56}$ included 23 patients with symptomatic vasospasm who subsequently received intraarterial infusions of fasudil for a total of 34 procedures. Angiographic vasospasm was assessed before and after treatment, and improvement was observed in all patients. Clinical outcome was also assessed immediately and at 3-month follow-up visits by using the Glasgow Outcome Scale score. Immediate neurological improvement was noted in 15 patients, and at the 3-month followup visit when the Glasgow Outcome Scale score was assessed; 15 (65.2\%) of the 23 patients showed good recovery or moderate disability. Because approximately half 
of the patients demonstrated clinical improvement and all had angiographic improvement, the investigators concluded that intraarterial fasudil was safe and effective for treatment of symptomatic cerebral vasospasm.

\section{Treatment-Related Complications}

No adverse effects were encountered in the study by Tachibana, et al. ${ }^{54}$ Blood pressure was monitored and did not decrease by more than $20 \mathrm{~mm} \mathrm{Hg}$ in any of the 10 cases. On the contrary, in the study by Tanaka, et al., ${ }^{56} \mathrm{a}$ significant decrease in mean systemic arterial pressure, from $139.0 \pm 3.4 \mathrm{~mm} \mathrm{Hg}$ to $126.8 \pm 3.6 \mathrm{~mm} \mathrm{Hg}(\mathrm{p}<$ $0.0001)$, was reported. These authors also noted a disturbance in consciousness that developed in two $(8.7 \%)$ of the 23 patients, which resolved within 1 hour. No other side effects were noted.

\section{Intraarterial Colforsin Daropate}

Colforsin daropate has positive chronotropic, inotropic, and coronary vasodilator actions and has been compared in the past with isoproterenol, dopamine, and dobutamine for its cardiovascular effects. ${ }^{60}$ Unlike the latter three drugs, colforsin daropate affects the cardiovascular variables in the following manner: coronary vasodilation $>>$ positive inotropy $>$ positive chronotropy. Isoproterenol, dopamine, and dobutamine have the following profile: positive inotropy $>>$ coronary vasodilation $>$ positive chronotropy. Because of its selectivity for vasodilation in coronary arteries, it has been speculated that this drug may also produce beneficial outcomes in the treatment of cerebral vasospasm.

\section{Mechanism of Action}

Colforsin daropate is a recently synthesized water-soluble forskolin derivative that directly activates adenylate cyclase. This causes an increase in intracellular cAMP concentrations. The cAMP facilitates calcium uptake into the sarcoplasmic reticulum, leading to a reduction in the amount of calcium available for smooth-muscle contraction. This chain of events is thought to lead to universal vasodilation in the arterial walls.

\section{Technique of Administration}

The use of colforsin daropate has only been described in two cases to date..$^{53}$ A No. 4 French diagnostic catheter was introduced via a transfemoral approach with the tip placed in the petrous portion of the left ICA in both cases. Three milligrams of colforsin daropate dissolved in 100 $\mathrm{ml}$ of physiological saline was infused at a rate of $5 \mathrm{ml} /$ minute. ${ }^{60}$

\section{Clinical Effects and Outcomes}

In the two published cases ${ }^{53}$ in which intraarterial colforsin daropate was used for the treatment of symptomatic vasospasm following $\mathrm{SAH}$, the patients presented with confusion, drowsiness, motor-dominant aphasia, and right hemiparesis, which improved remarkably after infusion. Angiography demonstrated prominent dilation of the vasospastic segment. In one case, on post-SAH Day 11, the patient again deteriorated neurologically with the same set of symptoms and was treated again with intraarterial colforsin daropate. This improvement persisted, and on follow-up examinations each patient was noted to be in good condition.

These two case studies are the first reported uses of intraarterial colforsin daropate. From them we can infer that endovascular therapy with colforsin daropate appears to be both safe and effective. Future prospective studies involving more patients need to be performed to evaluate further the efficacy and safety of this new agent.

\section{Treatment-Related Complications}

Suzuki, et al., ${ }^{53}$ reported no unfavorable side effects from the use of colforsin daropate to treat symptomatic vasospasm after SAH. Although the patient in Case 2 experienced a recurrence of vasospasm, it was effectively treated with another infusion of endovascular colforsin daropate.

\section{Conclusions}

Endovascular therapies should be considered when symptomatic cerebral vasospasm becomes refractory to maximal medical management. Transluminal balloon angioplasty is effective in dilating larger proximal vessels but its access for dilation of smaller distal vessels is limited. Intraarterial papaverine is effective in dilating both proximal and distal vasculature but is limited by its transient effects and risk of increased ICP. Other vasodilating agents, including nimodipine, nicardipine, verapamil, milrinone, fasudil, and colforsin daropate are currently being evaluated. Whether these agents are superior to papaverine awaits further studies. More investigation is needed to correlate improvement in $\mathrm{CBF}$ with clinical outcome after endovascular therapy.

\section{References}

1. Arakawa Y, Kikuta K, Hojo M, Goto Y, Ishii A, Yamagata S: Milrinone for the treatment of cerebral vasospasm after subarachnoid hemorrhage: report of seven cases. Neurosurgery 48:723-730, 2001

2. Arakawa Y, Kikuta K, Hojo M, Goto Y, Yamagata S, Nozaki $\mathrm{K}$, et al: Milrinone reduces cerebral vasospasm after subarachnoid hemorrhage of WFNS grade IV or V. Neurol Med Chir (Tokyo) 44:393-401, 2004

3. Awad IA, Carter LP, Spetzler RF, Medina M, Williams FC Jr: Clinical vasospasm after subarachnoid hemorrhage: response to hypervolemic hemodilution and arterial hypertension. Stroke 18:365-372, 1987

4. Badjatia N, Topcuoglu MA, Pryor JC, Rabinov JD, Ogilvy CS, Carter BS, et al: Preliminary experience with intra-arterial nicardipine as a treatment for cerebral vasospasm. AJNR Am J Neuroradiol 25:819-826, 2004

5. Bejjani GK, Bank WO, Olan WJ, Sekhar LN: The efficacy and safety of angioplasty for cerebral vasospasm after subarachnoid hemorrhage. Neurosurgery 42:979-987, 1998

6. Benashvili GM, Bernanke DH, Zubkov YN: Angioplasty rearranges collagen after subarachnoid hemorrhage, in Findlay JM (ed): Cerebral Vasospasm. Amsterdam: Elsevier, 1993, pp 341-344

7. Biondi A, Ricciardi GK, Puybasset L, Abdennour L, Longo M, Chiras $\mathrm{J}$, et al: Intra-arterial nimodipine for the treatment of symptomatic cerebral vasospasm after aneurysmal subarachnoid hemorrhage: preliminary results. AJNR Am J Neuroradiol 25:1067-1076, 2004 
8. Clouston JE, Numaguchi Y, Zoarski GH, Aldrich EF, Simard JM, Zitnay KM: Intraarterial papaverine infusion for cerebral vasospasm after subarachnoid hemorrhage. AJNR Am J Neuroradiol 16:27-38, 1995

9. Cook P, James I: Drug therapy: cerebral vasodilators (first of two parts). N Engl J Med 305:1508-1513, 1981

10. Cross DT III, Moran CJ, Angtuaco EE, Milburn JM, Diringer MN, Dacey RG Jr: Intracranial pressure monitoring during intraarterial papaverine infusion for cerebral vasospasm. AJNR Am J Neuroradiol 19:1319-1323, 1998

11. Dotter CT, Judkins MP: Transluminal treatment of arteriosclerotic obstruction. Description of a new technic and a preliminary report of its application. Circulation 30:654-670, 1964

12. Elliott JP, Newell DW, Lam DJ, Eskridge JM, Douville CM, Le Roux PD, et al: Comparison of balloon angioplasty and papaverine infusion for the treatment of vasospasm following aneurysmal subarachnoid hemorrhage. J Neurosurg 88: 277-284, 1998

13. Eskridge JM, McAuliffe W, Song JK, Deliganis AV, Newell DW, Lewis DH, et al: Balloon angioplasty for the treatment of vasospasm: results of first 50 cases. Neurosurgery 42: 510-517, 1998

14. Fandino J, Kaku Y, Schuknecht B, Valavanis A, Yonekawa Y: Improvement of cerebral oxygenation patterns and metabolic validation of superselective intraarterial infusion of papaverine for the treatment of cerebral vasospasm. J Neurosurg 89: 93-100, 1998

15. Feigin VL, Rinkel GJ, Algra A, Vermeulen M, van Gijn J: Calcium antagonists in patients with aneurysmal subarachnoid hemorrhage: a systematic review. Neurology 50:876-883, 1998

16. Feng L, Fitzsimmons BF, Young WL, Berman MF, Lin E, Aagaard BD, et al: Intraarterially administered verapamil as adjunct therapy for cerebral vasospasm: safety and 2-year experience. AJNR Am J Neuroradiol 23:1284-1290, 2002

17. Firlik AD, Kaufmann AM, Jungreis CA, Yonas H: Effect of transluminal angioplasty on cerebral blood flow in the management of symptomatic vasospasm following aneurysmal subarachnoid hemorrhage. J Neurosurg 86:830-839, 1997

18. Fujii Y, Takahashi A, Yoshimoto T: Effect of balloon angioplasty on high grade symptomatic vasospasm after subarachnoid hemorrhage. Neurosurg Rev 18:7-13, 1995

19. Haley EC Jr, Kassell NF, Torner JC: A randomized controlled trial of high-dose intravenous nicardipine in aneurysmal subarachnoid hemorrhage. A report of the Cooperative Aneurysm Study. J Neurosurg 78:537-547, 1993

20. Haley EC Jr, Kassell NF, Torner JC: A randomized trial of nicardipine in subarachnoid hemorrhage: angiographic and transcranial Doppler ultrasound results. A report of the Cooperative Aneurysm Study. J Neurosurg 78:548-553, 1993

21. Haley EC Jr, Kassell NF, Torner JC, Truskowski LL, Germanson TP: A randomized trial of two doses of nicardipine in aneurysmal subarachnoid hemorrhage. A report of the Cooperative Aneurysm Study. J Neurosurg 80:788-796, 1994

22. Handa Y, Weir BK, Nosko M, Mosewich R, Tsuji T, Grace M: The effect of timing of clot removal on chronic vasospasm in a primate model. J Neurosurg 67:558-564, 1987

23. Hoh BL, Ogilvy CS: Endovascular treatment of cerebral vasospasm: transluminal balloon angioplasty, intra-arterial papaverine, and intra-arterial nicardipine. Neurosurg Clin $\mathbf{N}$ Am 16:501-516, 2005

24. Hui C, Lau KP: Efficacy of intra-arterial nimodipine in the treatment of cerebral vasospasm complicating subarachnoid haemorrhage. Clin Radiol 60:1030-1036, 2005

25. Joshi S, Young WL, Pile-Spellman J, Duong DH, Hacein-Bey L, Vang MC, et al: Manipulation of cerebrovascular resistance during internal carotid artery occlusion by intraarterial verapamil. Anesth Analg 85:753-759, 1997

26. Kaku Y, Yonekawa Y, Tsukahara T, Kazekawa K: Superselective intra-arterial infusion of papaverine for the treatment of cerebral vasospasm after subarachnoid hemorrhage. J Neurosurg 77:842-847, 1992

27. Kassell NF, Helm G, Simmons N, Phillips CD, Cail WS: Treatment of cerebral vasospasm with intra-arterial papaverine. J Neurosurg 77:848-852, 1992

28. Kassell NF, Sasaki T, Colohan AR, Nazar G: Cerebral vasospasm following aneurysmal subarachnoid hemorrhage. Stroke 16:562-572, 1985

29. Kasuya H, Onda H, Takeshita M, Okada Y, Hori T: Efficacy and safety of nicardipine prolonged-release implants for preventing vasospasm in humans. Stroke 33:1011-1015, 2002

30. Khajavi K, Ayzman I, Shearer D, Jones SC, Levy JH, Prayson RA, et al: Prevention of chronic cerebral vasospasm in dogs with milrinone. Neurosurgery 40:354-363, 1997

31. Klimo P Jr, Kestle JR, MacDonald JD, Schmidt RH: Marked reduction of cerebral vasospasm with lumbar drainage of cerebrospinal fluid after subarachnoid hemorrhage. J Neurosurg 100:215-224, 2004

32. Kodama N, Mizoi K, Sakurai Y, Suzuki J: Incidence and onset of vasospasm, in Wilkins RH (ed): Cerebral Arterial Spasm. Philadelphia: Williams \& Wilkins, 1980, pp 361-365

33. Liu JK, Couldwell WT: Intra-arterial papaverine infusions for the treatment of cerebral vasospasm induced by aneurysmal subarachnoid hemorrhage. Neurocrit Care 2:124-132, 2005

34. Liu JK, Tenner MS, Gottfried ON, Stevens EA, Rosenow JM, Madan N, et al: Efficacy of multiple intraarterial papaverine infusions for improvement in cerebral circulation time in patients with recurrent cerebral vasospasm. J Neurosurg 100:414-421, 2004

35. McAuliffe W, Townsend M, Eskridge JM, Newell DW, Grady MS, Winn HR: Intracranial pressure changes induced during papaverine infusion for treatment of vasospasm. J Neurosurg 83:430-434, 1995

36. Milburn JM, Moran CJ, Cross DT III, Diringer MN, Pilgram TK, Dacey RG Jr: Effect of intraarterial papaverine on cerebral circulation time. AJNR Am J Neuroradiol 18:1081-1085, 1997

37. Milburn JM, Moran CJ, Cross DT III, Diringer MN, Pilgram TK, Dacey RG Jr: Increase in diameters of vasospastic intracranial arteries by intraarterial papaverine administration. J Neurosurg 88:38-42, 1998

38. Murai Y, Kominami S, Kobayashi S, Mizunari T, Teramoto A: The long-term effects of transluminal balloon angioplasty for vasospasms after subarachnoid hemorrhage: analyses of cerebral blood flow and reactivity. Surg Neurol 64:122-127, 2005

39. Newell DW, Elliott JP, Eskridge JM, Winn HR: Endovascular therapy for aneurysmal vasospasm. Crit Care Clin 15: 685-699, 1999

40. Newell DW, Eskridge J, Mayberg M, Grady MS, Lewis D, Winn HR: Endovascular treatment of intracranial aneurysms and cerebral vasospasm. Clin Neurosurg 39:348-360, 1992

41. Ohkuma H, Manabe H, Tanaka M, Suzuki S: Impact of cerebral microcirculatory changes on cerebral blood flow during cerebral vasospasm after aneurysmal subarachnoid hemorrhage. Stroke 31:1621-1627, 2000

42. Oskouian RJ Jr, Martin NA, Lee JH, Glenn TC, Guthrie D, Gonzalez NR, et al: Multimodal quantitation of the effects of endovascular therapy for vasospasm on cerebral blood flow, transcranial doppler ultrasonographic velocities, and cerebral artery diameters. Neurosurgery 51:30-43, 2002

43. Pickard JD, Murray GD, Illingworth R, Shaw MD, Teasdale GM, Foy PM, et al: Effect of oral nimodipine on cerebral infarction and outcome after subarachnoid haemorrhage: British aneurysm nimodipine trial. BMJ 298:636-642, 1989

44. Polin RS, Coenen VA, Hansen CA, Shin P, Baskaya MK, Nanda A, et al: Efficacy of transluminal angioplasty for the management of symptomatic cerebral vasospasm following aneurysmal subarachnoid hemorrhage. J Neurosurg 92: 284-290, 2000 


\section{Endovascular therapies for cerebral vasospasm after aneurysmal SAH}

45. Polin RS, Hansen CA, German P, Chadduck JB, Kassell NF: Intra-arterially administered papaverine for the treatment of symptomatic cerebral vasospasm. Neurosurgery 42: 1256-1264, 1998

46. Rabinstein AA, Friedman JA, Nichols DA, Pichelmann MA, McClelland RL, Manno EM, et al: Predictors of outcome after endovascular treatment of cerebral vasospasm. AJNR Am J Neuroradiol 25:1778-1782, 2004

47. Rasmussen G, Bergholdt B, Dalh B, Sunde N, Cold G, Voldby B: Effect of nimodipine on cerebral blood flow and cerebrovascular reactivity after subarachnoid haemorrhage. Acta Neurol Scand 99:182-186, 1999

48. Rosenwasser RH, Armonda RA, Thomas JE, Benitez RP, Gannon PM, Harrop J: Therapeutic modalities for the management of cerebral vasospasm: timing of endovascular options. Neurosurgery 44:975-980, 1999

49. Sawada M, Hashimoto N, Tsukahara T, Nishi S, Kaku Y, Yoshimura S: Effectiveness of intra-arterially infused papaverine solutions of various concentrations for the treatment of cerebral vasospasm. Acta Neurochir (Wien) 139:706-711, 1997

50. Schuknecht B: Endovascular treatment of cerebral vasospasm following aneurysmal subarachnoid hemorrhage. Acta Neurochir Suppl 94:47-51, 2005

51. Shibuya M, Suzuki Y, Sugita K, Saito I, Sasaki T, Takakura K, et al: Effect of AT877 on cerebral vasospasm after aneurysmal subarachnoid hemorrhage. Results of a prospective placebocontrolled double-blind trial. J Neurosurg 76:571-577, 1992

52. Smith TP, Enterline DS: Endovascular treatment of cerebral vasospasm. J Vasc Interv Radiol 11:547-559, 2000

53. Suzuki S, Ito O, Sayama T, Yamaguchi S, Goto K, Sasaki T: Intraarterial injection of colforsin daropate hydrochloride for the treatment of vasospasm after aneurysmal subarachnoid hemorrhage: preliminary report of two cases. Neuroradiology 48:50-53, 2006

54. Tachibana E, Harada T, Shibuya M, Saito K, Takayasu M, Suzuki Y, et al: Intra-arterial infusion of fasudil hydrochloride for treating vasospasm following subarachnoid haemorrhage. Acta Neurochir (Wien) 141:13-19, 1999

55. Takis C, Kwan ES, Pessin MS, Jacobs DH, Caplan LR: Intracranial angioplasty: experience and complications. AJNR Am J Neuroradiol 18:1661-1668, 1997
56. Tanaka K, Minami H, Kota M, Kuwamura K, Kohmura E: Treatment of cerebral vasospasm with intra-arterial fasudil hydrochloride. Neurosurgery 56:214-223, 2005

57. Tsurushima H, Kamezaki T, Nagatomo Y, Hyodo A, Nose T: Complications associated with intraarterial administration of papaverine for vasospasm following subarachnoid hemorrhage-two case reports. Neurol Med Chir (Tokyo) 40: $112-115,2000$

58. Vajkoczy P, Horn P, Bauhuf C, Munch E, Hubner U, Ing D, et al: Effect of intra-arterial papaverine on regional cerebral blood flow in hemodynamically relevant cerebral vasospasm. Stroke 32:498-505, 2001

59. Varsos VG, Liszczak TM, Han DH, Kistler JP, Vielma J, Black PM, et al: Delayed cerebral vasospasm is not reversible by aminophylline, nifedipine, or papaverine in a "two-hemorrhage" canine model. J Neurosurg 58:11-17, 1983

60. Yoneyama M, Sugiyama A, Satoh Y, Takahara A, Nakamura Y, Hashimoto K: Cardiovascular and adenylate cyclase stimulating effects of colforsin daropate, a water-soluble forskolin derivative, compared with those of isoproterenol, dopamine and dobutamine. Circ J 66: 1150-1154, 2002

61. Yoshida K, Watanabe H, Nakamura S: Intraarterial injection of amrinone for vasospasm induced by subarachnoid hemorrhage. AJNR Am J Neuroradiol 18:492-496, 1997

62. Zubkov AY, Lewis AI, Scalzo D, Bernanke DH, Harkey HL: Morphological changes after percutaneous transluminal angioplasty. Surg Neurol 51:399-403, 1999

63. Zubkov YN, Nikiforov BM, Shustin VA: Balloon catheter technique for dilatation of constricted cerebral arteries after aneurysmal SAH. Acta Neurochir (Wien) 70:65-79, 1984

Manuscript received June 16, 2006.

Accepted in final form August 4, 2006.

Address reprint requests to: William T. Couldwell, M.D, Department of Neurosurgery, University of Utah, 30 North 1900 East, Suite 3B409, Salt Lake City, Utah 84132. email: william. couldwell@hsc.utah.edu. 